\title{
Educated Unemployed, Educational Subsidies and Growth
}

\author{
T. DATTA CHAUDHURI and M. ALI KHAN*
}

\section{INTRODUCTION}

The subject matter of the present study is educated unemployment, a commonly observed phenomenon, especially in some of the more populous LDCs like India. Such an inquiry is warranted for two different reasons. First of all, it is a common observation that educated unemployment does not deter the demand for education; see, for example, Blaug et al. [3]. The question that needs to be answered is why do people go in for education in spite of this widespread unemployment? Secondly, it is an important policy question for governments of such LDCs as to whether education should be subsidized or not. Whereas the long-term gains in productivity accruing from a more educated labour force are undeniable, there is now also a growing realization that educational subsidies, by affecting educational costs, have a part to play in increased educated unemployment. In addition, such subsidies, being financed by taxes, reduce disposable income and hence further reduce an already inadequate supply of domestic savings for physical capital formation.

It is clear that an analysis of these issues must begin in terms of a general equilibrium model which is explicitly dynamic in nature and in which individuals' decision to educate their children takes the number of educated unemployed into account. We present such a model here. It incorporates into a recent contribution of Findlay and Rodriguez (FR) [5] an insight which can be traced to the rate-ofreturn calculations presented in Blaug et al. [3]. Our model may well have applicability to other problems as well.

We work with an economy in which there are two sectors, three inputs and two assets. The three inputs are educated labour, uneducated labour and capital. The two assets are physical and human capital. Since the educated are more productive, the firms are willing to pay them a higher wage than the uneducated. We assume that 
the wage of the educated is institutionally fixed and hence impedes clearing of that market. The unemployment resulting from rigid wages ${ }^{1}$ governs the expected return from education. This is the idea used by [3] in their empirical calculations of the rate of return from education and is now well known in the context of intersectoral migration as the Harris-Todaro hypothesis. ${ }^{2}$ It is thus that the unemployment rate enters into intertemporal decision-making and affects the long-run composition of the labour force.

The plan of the paper is as follows. In Section II we briefly describe the FR model and then introduce unemployment. An analysis of the temporary equilibrium of the model is done in Section III and the static or short-run implications of educational subsidies are derived. Section IV deals with the dynamics of the model. The long-run implications of changes in educational subsidies and in the savings properisity are analysed here. Section V concludes the paper with a summary of results.

\section{THE MODEL}

Let the economy produce a "Solow-good"3 $Q$ which can be both consumed and accumulated in the form of physical capital and which uses as inputs capital and both kinds of labour, educated and uneducated. Inputs and output are related by a production function

$$
Q=Q\left(K_{q}, E_{q}, U\right)
$$

which is homogeneous of degree one, twice continuously differentiable and strictly concave. $K_{q}$ and $E_{q}$ stand for capital and educated labour used in the $Q$-sector and $U$ is the number of the uneducated in the economy.

Let the population of the economy as a whole grow at an exogenously given rate $n$, i.e.

$$
N(t)=N(0) e_{\substack{n t \\ \text { st }}}
$$

So $n N(t)$ stands for the increase in population, of which a part gets educated and a part remains uneducated. The process of transforming the additional population into educated labour is captured in the production function

$$
X=X\left(K_{x}, E_{x}\right)
$$

${ }^{1}$ Bhagwati and Srinivasan [2] have also assumed sticky wages of the educated. But instead of persisting educated unemployment make the unemployed further down the "Job Ladder". A more substantive difference from our work is that they do not allow for capital accumulation.

${ }^{2}$ See Harris and Todaro [6]

${ }^{3}$ See Solow [9]. where $X$ is the number of additional educated produced with capital and educated labour. Constant return to scale is assumed in the production of "schooling." We also assume $X(\cdot)$ to be twice continuously differentiable and strictly concave. $K$ and $E_{x}$ stand for capital and educated labour employed in this sector.

At any point in time the economy starts out with a given capital stock $K$ and a given population $N$, where the division of $N$ between educated $E$ and uneducated $U$ is also given. Thus, we have

$$
\begin{aligned}
& K_{q}+K_{x}=K \\
& E+U=N \\
& E_{q}+E_{x}=E(1-\lambda)
\end{aligned}
$$

where $\lambda$ is the ratio of educated unemployed to total educated population.

The allocations of $E_{i}$ and $K_{i}, i=q, x$ are determined by marginal productivity pricing, i.e.

$$
\begin{aligned}
& \frac{\partial Q}{\partial K_{q}}=p \frac{\partial X}{\partial K_{x}}=r \\
& \frac{\partial Q}{\partial E_{q}}=p \frac{\partial X}{\partial F_{x}}=w_{e}
\end{aligned}
$$

where $r$ is the return from capital and $w_{e}$ is the wage of the educated. $p$ represents the price of schooling and, following FR, we have assumed the price of good $Q$ to be the numeraire equal to unity. We have full employment of the uneducated and they are also paid their marginal product, i.e.

$$
\frac{\partial Q}{\partial U}=w_{u}
$$

where $w_{u}$ is the wage of the uneducated. The wage rate of the educated is assumed to be given, i.e.

$$
w_{e}=\bar{w}_{e}
$$

In $\mathrm{FR}$, the decision of workers to educate their children is given by $r=\frac{w_{e}-w_{u}}{p}$. It is this equilibrium condition that governs allocation of savings. It 
states that under static expectations, in equilibrium, the rates of return from investing in capital or going through schooling ${ }^{4}$ must be the same. In the presence of unemployment, we modify this equilibrium condition to

$$
r=\frac{\bar{w}_{e} \cdot \frac{1}{1+\lambda^{\prime}}-w_{u}}{p}
$$

where $\lambda^{\prime}=\lambda / 1-\lambda, \lambda$ as defined above and with $(1-\lambda)$ the probability of getting a job by the educated. Since $d \lambda^{\prime} / d \lambda>0$, we can work throughout with $\lambda^{\prime}$ instead of $\lambda$ in (2.11).

Equation (2.11) represents three things. First, it captures the fact that in the presence of unemployment, individuals will invest in education on the basis of differences in expected incomes rather than those in actual incomes. Secondly, it takes into account costs of education. Thirdly, the presence of the rate of return on investment shows alternative against which investment in education is being evaluated. Indeed, a justification for using equation (2.11) can be found in Chapters 8 and 9 in Blaug [3].

\section{ANALYSIS OF THE TEMPORARY EQUILIBRIUM}

We relegate the study of the dynamics of human and physical capital formation to the next section and focus here on the analysis of a temporary equilibrium of our model, i.e. with the stock of capital and labour exogenously given. This involves finding factor rewards, allocation of capital and labour resources, and rate of unemployment, the costs of schooling and allocation of savings between the two assets.

Given constant returns to scale, we can write down the cost functions in each sector as

$$
\begin{aligned}
& 1=C_{q}\left(\bar{w}_{e}, w_{u}, r\right) \\
& p=C_{x}\left(\bar{w}_{e}, r\right)
\end{aligned}
$$

Since $\bar{w}_{e}$ is fixed, we have two equations in three unknowns. On determining $w_{u}$ and $r$ in terms of $p$ it is easy to see that $\frac{\partial r}{\partial p}>0$ and $\frac{\partial w_{u}}{\partial p}<0$.

${ }^{4}$ The "rate of return" argument for getting educated is present in Becker [1], and, for example, in Razin [7] and his references. This in literature is partial equilibrium in the sense that it does not consider production of education as an activity that uses scarce resources. However, its explanation for getting educated is more detailed than ours.
Rewriting (2.4), (2.5) and (2.6), we obtain

$$
\begin{aligned}
\frac{K_{q}}{Q} q+\frac{K_{z}}{X} x & =k \\
\frac{E_{q}}{Q} q+\frac{E_{x}}{X} x & =e(1-\lambda) \\
\frac{U}{Q} q & =1-e
\end{aligned}
$$

where $q=\frac{Q}{N}, x=\frac{X}{N}, k=\frac{K}{N}$ and $e=\frac{E}{N}$. Once $w_{u}$ and $r$ are determined, the input-output ratios are also uniquely determined. The three equations, (3.3), (3.4) and (3.5), can then be solved for $q, x$ and $\lambda$. Total differentiation of (3.3) and (3.5) yields

$$
\left[\begin{array}{ll}
\frac{K_{q}}{Q} & \frac{K_{x}}{X} \\
\frac{U}{Q} & 0
\end{array}\right]\left[\begin{array}{l}
d q \\
d x
\end{array}\right]\left[\begin{array}{l}
d k \cdot d p\left[q\left(\frac{\partial^{2} C_{q}}{\partial r^{2}} \cdot \frac{\partial r}{\partial p}+\frac{\partial^{2} C_{q}}{\partial r \partial w_{u}} \cdot \frac{\partial w_{u}}{\partial p}\right)+x\left(\frac{\partial^{2} C_{x}}{\partial r^{2}} \cdot \frac{\partial r}{\partial p}\right)\right] \\
-d e-d p\left[q\left(\frac{\partial^{2} C_{q} \partial w_{u}}{\partial w_{u}^{2} \partial p}+\frac{\partial^{2} C_{q}}{\partial w_{u} \partial r} \cdot \frac{\partial r}{\partial p}\right)\right]
\end{array}\right]
$$

The first point to be noted is that assumptions on factor substitutability, as opposed to those on factor intensities, are sufficient to determine the Rybczynski effects. Henceforth we shall assume that capital is a substitute for both kinds of labour, but educated and uneducated labour are complements. We derive rather unusual Rybczynski effects. An increase in capital-labour ratio keeps output of the Q-sector unchanged. Again, given $p$, we can see from (3.5) that an increase in $e$ will reduce $q$ since there is always full employment of uneducated labour. These imply that an increase in either capital per head or in the proportion of educated in total population will increase the number of newly educated. The price effects are normal in this model, i.e. $\frac{d q}{d p}<0$ and $\frac{d x}{d p}>0$.

We can now determine $\lambda$ by totally differentiating (3.4) to obtain

$\left\{q\left[\frac{\partial^{2} C_{q} \partial w_{u}}{\partial w_{e} \partial w_{u} \partial p}+\frac{\partial^{2} C_{q} \partial r}{\partial w_{e} \partial r \partial p}\right]+x\left[\frac{\partial^{2} c_{x} \partial r}{\partial w_{e} \partial r \partial p}\right]\right\} d p+\frac{E_{q}}{Q} d q+\frac{E_{x}}{X} d x=(1-\lambda)$ de-ed 
We have already seen that an increase in capital per head increases $x$ and keeps $q$ unchanged. Under incomplete specialization, this implies that employment of the educated will rise. Equation (3.7) yields $\frac{d \lambda}{d k}<0$, i.e. an increase in the capitallabour ratio decreases educated unemployment. An increase in $e$, however, increases $x$ but reduces $q$. So on the one hand, some of the educated employed are released from work and, on the other, there is an increased demand for them. Here we make an assumption about factor intensities to determine the movement in the unemployment rate. We assume that the Solow-good sector is more education-intensive than the education-producing sector, i.e. $\frac{E_{q}}{K_{q}}>\frac{E_{x}}{K_{x}}$. Equation (3.7) then yields $\frac{d \lambda}{d e}>0$, i.e. an increase in the proportion of the educated in the total population increases educated unemployment.

From the point of view of the analysis to follow, it is important that $\frac{d \lambda}{d p}$ cannot be unambiguously signed. On the one hand, an increase in $p$ reduces $q$ but increases $x$. Since the $q$-producing sector is more education-intensive than the $x$ producing sector, there is a tendency for an increase in the number of the educated unemployed. But again an increase in $p$, causing $r$ to rise, makes labour relatively cheap and leads to substitution in favour of labour. This raises the use of educated labour per unit of output and tends to reduce the number of the educated unemployed. Equation (3.7) shows the above-mentioned set of factors whose relative strengths will determine the sign of $\frac{d \lambda}{d p}$.

Our analysis thus far has assumed the costs of schooling to be given along with the initial endowments of capital and labour. We now use (2.11) to determine $p$. We have already noted that (2.11) specifies a rule for allocation of savings. This is an equation which also reflects demand for education. To understand this, the following causality is suggested (although all the variables are solved simultaneously). From the production side, any given value of $p$ determines factor prices, allocation of resources and the rate of unemployment. Since certain demand conditions gave rise to that initial $p$, the unemployment rate is a result of both rigid wages and demand considerations. From the point of view of demand for education, once factor rewards and the unemployment rate are given, allocation of savings determines the demand price for education. In equilibrium the initial price we started with and the end price we derive must be the same. The causality enables us (a) to interpret R.H.S. of (2.11) as demand and (b) to understand that the unemployment rate does not play a role in static allocation of resources but figures prominently in intertemporal decision-making.
We now move on to a study of the output and employment effects of educational subsidies in this temporary equilibrium setting. In the presence of such subsidies, (2.11) gets modified to

$$
r=\frac{\bar{w}_{e} \cdot \frac{1}{1+\lambda^{\prime}}-w_{u}}{p(1-\tau)}
$$

where $\tau$ is the subsidy rate. Since $r, w_{u}$ and $\lambda$ are all functions of $p$,

$$
\frac{d p}{d \tau}=\frac{\tau p}{p(1-\tau) \frac{\partial r}{\partial p}+r(1-\tau)+\frac{\partial w_{u}}{\partial p}+\frac{\bar{w}_{e} d \lambda^{\prime}}{\left(1+\lambda^{\prime}\right)^{2} d p}}
$$

As the R.H.S. of (2.11) can be given a demand interpretation, the L.H.S. can be given a supply interpretation. In equilibrium we determine a $p^{*}$ that equates the demand for savings for education to the supply of savings for that purpose. For the analysis to follow it is important that the temporary equilibrium be stable. We have observed that the model set out so far could be decomposed into different subsystems and solved in terms of $p$. So if we can show that any movement away from $p^{*}$ brings us back to $p^{*}$, then we can conclude that the temporary equilibrium is stable. For stability we assume the following adjustment process

$$
\dot{p}=H\left[\frac{\frac{\bar{w}_{e}}{1+\lambda^{\prime}} w_{u}}{p(1-\tau)}-r\right], H^{\prime}>0, H(0)=0
$$

Equation (3.10) states that if the expected gain from investing in education is greater than the rate of return from holding capital goods, then an increased demand for education will drive up the costs of schooling. We have already seen that the R.H.S. of the differential equation is a function of $p$. Linearizing it around $p^{*}$ yields

$$
-\frac{H^{\prime}}{p(1-\tau)}\left[p(1-\tau) \frac{\partial r}{\partial p}+r(1-\tau)+\frac{\bar{w}_{e}}{\left(1+\lambda^{\prime}\right)^{2}} \frac{d \lambda^{\prime}}{d p}+\frac{\partial w_{u}}{\partial p}\right]
$$

For stability of the temporary equilibrium, the expression in (3.11) has to be negative. This, in turn, implies $\frac{d p}{d \tau}>0$. Note that this result is no way contingent on a definitive sign of $\frac{d \lambda^{\prime}}{d p}$. Hence our conjecture about educational subsidies increasing educated unemployment in the short run is valid only under certain conditions. 
We conclude this section with an observation. Since the unemployment rate is a function of initial endowments of capital and educated labour, so is $p$. This is an important distinction from the FR model, since it results in physical and human capital formation affecting the costs of schooling. The significance of this for the growth path of our economy will become clear in the next section. Here we simply note that the direction of changes in $p$ with changes in $k$ and $e$ are given by the following formulae

$$
\begin{aligned}
& \frac{d p}{d k}=\frac{\frac{\bar{w}_{e}}{(1+\lambda)^{2}} \frac{d \lambda}{d k}}{p(1-\tau) \frac{\partial r}{\partial p}+r(1-\tau)+\frac{\partial w_{u}}{\partial p}+\frac{\bar{w}_{e}}{(1+\lambda)^{2}} \frac{d \lambda^{\prime}}{d p}}>0 \\
& \frac{d p}{d e}=-\frac{\frac{\bar{w}_{e}}{(1+\lambda)^{2}} \frac{d \lambda}{d e}}{p(1-\tau) \frac{\partial r}{\partial p}+r(1-\tau)+\frac{\partial w_{u}}{\partial p}+\frac{\bar{w}_{e}}{(1+\lambda)^{2}} \frac{d \lambda^{\prime}}{d p}}<0
\end{aligned}
$$

\section{ACCUMULATION OF PHYSICAL AND HUMAN CAPITAL}

Here we show first that once schooling costs change with growth in the economy, the stability of the steady-state can no longer be guaranteed. Then we derive the effects of educational subsidies and changes in the saving propensity on the steady-state values of $k$ and $e$.

In temporary equilibrium, the allocation of resources determines the number of newly born who are to be educated and, hence, determines the volume of savings that have to be allocated for that purpose. Moreover, we assume that educational subsidies are financed by a general income tax. So the amount of savings that finances investment in capital goods is given by $s[Q+p X-\tau p X]-p X$. In equilibrium

$$
\frac{d K}{d t}=\dot{K}=s[Q+p X-\tau p X]-p X
$$

Since $X$ represents addition to the educated labour force, we have

$$
\frac{d E}{d t}=\dot{E}=X
$$

It is easy to see that the above two differential equations can be rewritten in per capita terms as

$$
\begin{aligned}
& \dot{k}=s[q+(1-\tau) p x]-p x-n k \\
& \dot{e}=x-n e
\end{aligned}
$$

Equations (4.3) and (4.4) constitute the dynamic system. An equilibrium is characterized by $k^{*}, e^{*}$ where $\dot{k}=\dot{e}=0$. For stability, the four partial derivatives are readily obtained as

$$
\begin{aligned}
& \frac{\partial \dot{k}}{\partial k}=s \frac{\partial q}{\partial k}+[s(1-\tau)-1] \quad\left[x \frac{\partial p}{\partial k}+p \frac{\partial x}{\partial k}\right]-n \\
& \frac{\partial \dot{k}}{\partial e}=s \frac{\partial q}{\partial e}+[s(1-\tau)-1] \quad\left[x \frac{\partial p}{\partial e}+p \frac{\partial x}{\partial e}\right] \\
& \frac{\partial \dot{e}}{\partial k}=\frac{\partial x}{\partial k} \\
& \frac{\partial \dot{e}}{\partial e}=\frac{\partial x}{\partial e}-n .
\end{aligned}
$$

It can be checked that $\frac{\partial \dot{k}}{\partial k}<0$ and $\frac{\partial \dot{e}}{\partial k}>0$. The signs of $\frac{\partial \dot{e}}{\partial e}$ and $\frac{\partial \dot{k}}{\partial e}$ cannot be unambiguously determined and these have implications with respect to stability of the model. For example, if $\frac{\partial \dot{e}}{\partial e}>0$ and $\frac{\partial \dot{k}}{\partial e}<0$ such that $\frac{\partial \dot{k}}{\partial k}+\frac{\partial \dot{e}}{\partial e}>0$ and $\frac{\partial \dot{k}}{\partial \mathrm{k}} \cdot \frac{\partial \dot{e}}{\partial e}-\frac{\partial \dot{k}}{\partial e} \cdot \frac{\partial \dot{e}}{\partial k}>0$, then the system is unstable. Again, if $\frac{\partial \dot{e}}{\partial e}$ and $\frac{\partial \dot{k}}{\partial e}$ are such that $\frac{\partial \dot{k}}{\partial k} \cdot \frac{\partial \dot{e}}{\partial e}-\frac{\partial \dot{k}}{\partial e} \cdot \frac{\partial \dot{e}}{\partial k}<0$, then the equilibrium is a saddle-point. Thus, the stability property of the FR model is only a possible case. Since we shall be discussing policy measures, we shall consider situations which are stable only. This includes the situation in which the system has a stable branch. Comparative static exercises in the presence of a saddle-point equilibrium have been performed, among others, by Calvo and Rodriguez [4] and Obstfeld [8] with the perfect foresight assumption underlying such calculations. We adopt the same assumption here.

The evolution of the economy towards a steady state is shown in Figure 1. Under different assumptions about $\frac{d \dot{e}}{d e}$ and $\frac{\partial \dot{k}}{\partial e}$, the equilibrium is either overall stable, or is a saddle-point. Altogether six possible cases arise and the corresponding phase diagrams are depicted in Figure 1. 
(a)

(b)

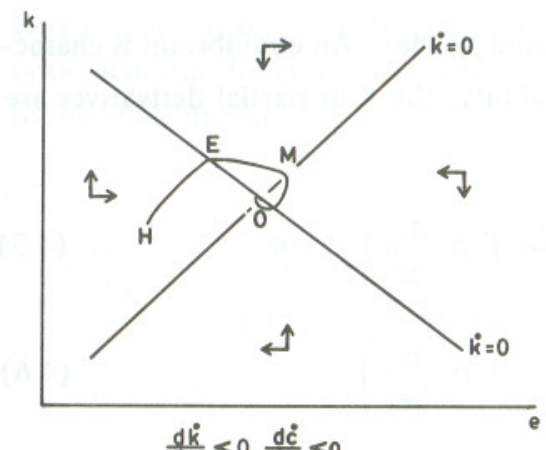

$\frac{d \dot{k}}{d c}<0, \frac{d \dot{c}}{d e}<0$

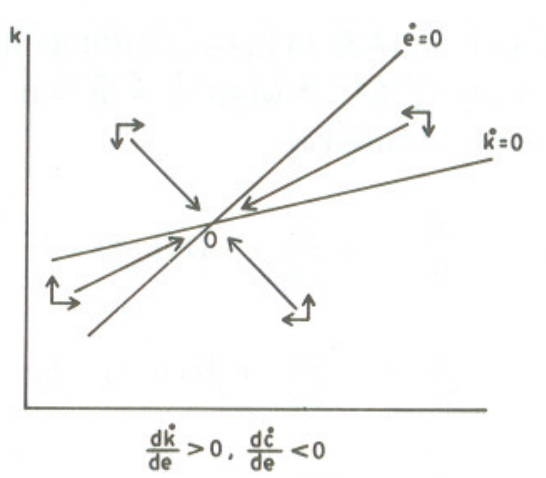

$\frac{d \dot{k}}{d e}>0, \frac{d \dot{i}}{d e}<0$ (d)

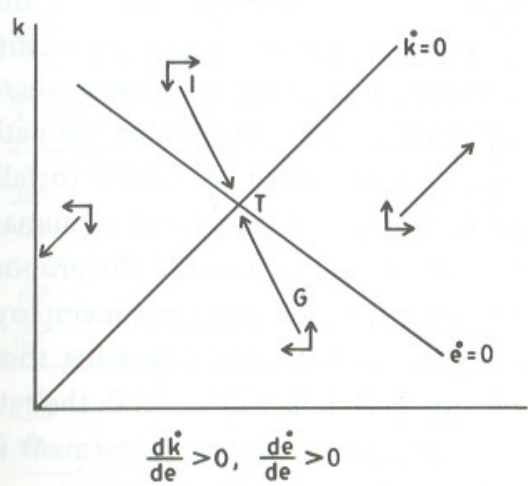

(e)

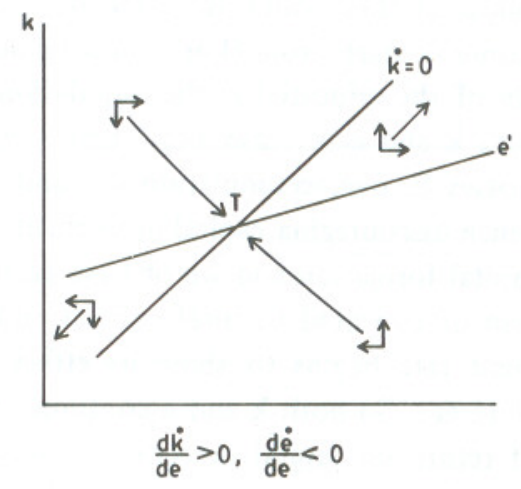

(c)

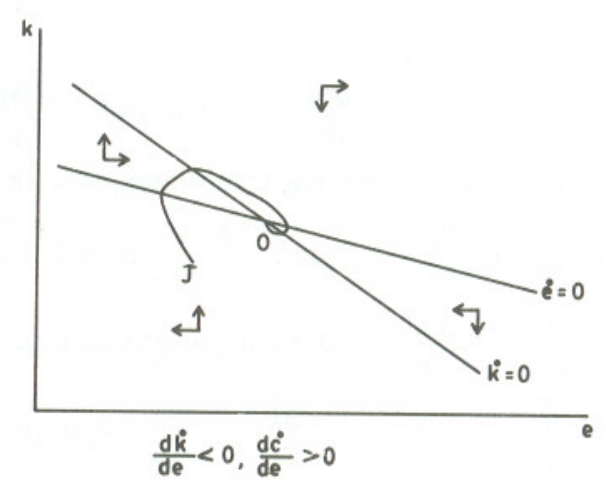

(f)

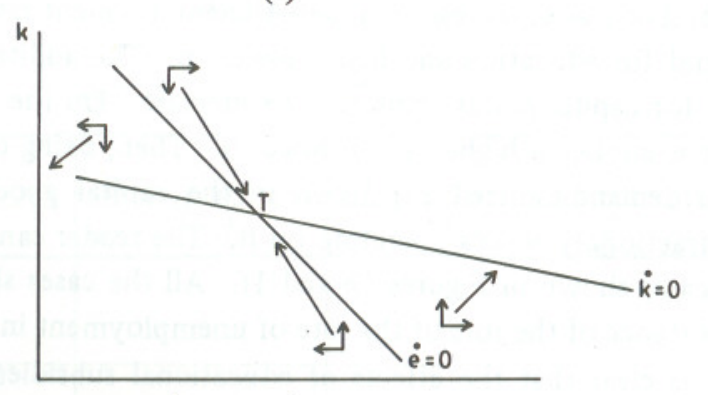

$\frac{d \dot{k}}{d e}<0, \frac{d \dot{e}}{d e}>0$

Fig. 1 Dynamic paths of $\mathbf{k}$ and $\mathrm{e}$ where $\left(\mathrm{k}^{*}, \mathrm{e}^{*}\right)$ is a saddle-point under different conditions on the rates of change of $k$ and $e$.

Fig. 1 Dynamic paths of $\mathbf{k}$ and $\mathrm{e}$ where $\left(\mathrm{k}^{*}, \mathrm{e}^{*}\right)$ is overall stable under different conditions on the rates of change of $k$ and $e$. These rates of changes are evaluated at $\left(\mathrm{k}^{*}, \mathrm{e}^{*}\right)$. 
Figures $1 \mathrm{a}, 1 \mathrm{~b}$ and $1 \mathrm{c}$ show that the steady state is overall stable. A possibility of cyclical convergence is shown in 1a and 1c. The trajectories the system may follow in these cases are given by the lines drawn through $\mathbf{H}$ and J. Suppose the economy starts from $\mathbf{H}$ or $\mathbf{J}$ showing initial levels of the capital intensity and percentage of the educated in the population. It is interesting how there are phases where both $\mathrm{k}$ and $\mathrm{e}$ increase and where they both fall. In Figure 1a, as soon as the path crosses $\mathrm{E}$, overaccumulation of capital forces the rate of return on capital to fall, hence discouraging capital investment. The resulting savings are reallocated to human capital formation and we observe an increase in e. As the path crosses $\mathrm{M}$ the proportion of educated to total population becomes so high that the resulting unemployment rate begins to show its effect in discouraging parents from educating their children. So both $\mathrm{k}$ and e continue to drop. As the path falls below $\dot{\mathrm{k}}=0$, the rate of return on capital exceeds the rate of return on education, causing investment in capital and an eventual increase in $\mathrm{k}$. Figure $1 \mathrm{~b}$ shows monotonic convergence.

A possibility of a saddle-point equilibrium is shown in Figures 1d, 1e and 1f. Observe that the stable branch is downward sloping. Hence a point like $G$ shows overaccumulation of human capital, causing e to fall and $\mathrm{k}$ to rise. The opposite is true for trajectories starting from I. The possibility of a saddle-point equilibrium as shown in Figure 1d arises from the following considerations. Compared with T, a higher level of $\mathrm{e}$ at $\mathrm{G}$ represents a higher unemployment rate. This causes a reduction in demand for education and hence lowers $\mathrm{p}$. The additional savings translate into demand for capital goods, causing $\mathrm{k}$ to increase. On the production side, however, a higher e implies a higher $\mathrm{x}$ and lower $\mathrm{q}$. Then, being on a saddle branch implies that the demand-induced expansion in the capital goods sector overcompensates the contractionary forces operating on it. The reader can work out a similar reasoning for cases shown in Figures 1e and 1f. All the cases shown in Figure 1 bring out the importance of the role of the rate of unemployment in the adjustment process.

It is clear that the effects of educational subsidies or changes in the saving propensity on steady-state values of $k$ and $e$ will depend on whether the equilibrium is a saddle-point or not. These results are derived below and summarised in Tables A and B. On totally differentiating (4.3) and (4.4) at equilibrium characterized by $\dot{k}=\dot{e}=0$, we obtain

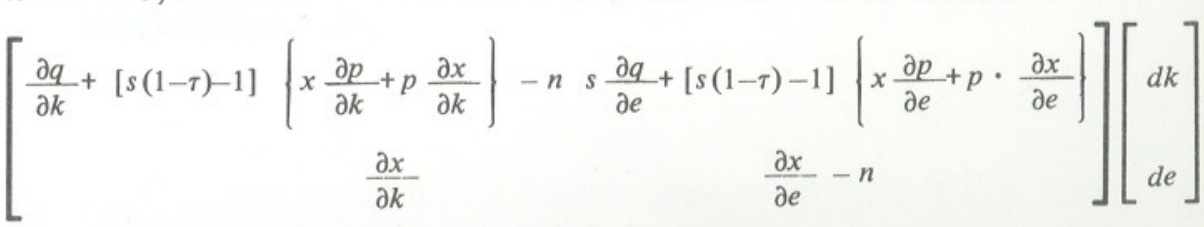

Table A

Overall Stable System

\begin{tabular}{|c|c|c|c|c|}
\hline Then & $\frac{d \dot{k}}{d e}>0, \frac{d \dot{e}}{d e}>0^{*}$ & $\frac{d \dot{k}}{d e}<0, \frac{d \dot{e}}{d e}<0$ & $\frac{d \dot{k}}{d e}>0, \frac{d \dot{e}}{d e}<0$ & $\frac{d \dot{k}}{d e}<0, \frac{d \dot{e}}{d e}>0$ \\
\hline$\frac{d k}{d \tau}$ & - & $<0$ & 2 & 3 \\
\hline$\frac{d e}{d \tau}$ & - & 4 & 5 & $?$ \\
\hline$\frac{d k}{d s}$ & - & $>0$ & $>0$ & $<0$ \\
\hline$\frac{d e}{d s}$ & - & $>0$ & $>0$ & $>0$ \\
\hline
\end{tabular}

*In this situation the equilibrium is a saddle-point.

Table B

$\left(\mathrm{k}^{*}, \mathrm{e}^{*}\right)$ is a Saddle-Point

\begin{tabular}{l|cr|c|c|c|c}
\hline If & $\frac{d \dot{k}}{d e}>0, \frac{d \dot{e}}{d e}>0$ & $\frac{d \dot{k}}{d e}<0, \frac{d \dot{e}}{d e}<0 *$ & $\frac{d \dot{k}}{d e}>0, \frac{d \dot{e}}{d e}<0$ & $\frac{d \dot{k}}{d e}<0, \frac{d \dot{e}}{d e}>0$ \\
\hline$\frac{d k}{d \tau}$ & $<0$ & 1 & - & $?$ & $?$ \\
\hline$\frac{d e}{d \tau}$ & $?$ & 4 & - & $?$ & 5 & $?$ \\
\hline$\frac{d k}{d s}$ & $>0$ & 7 & - & $<0$ & 8 \\
\hline$\frac{d e}{d s}$ & $<0$ & 10 & - & $<0$ & 11 & $<0$ \\
\hline
\end{tabular}

*In this situation the system is stable overall. 
Let us first consider the effects of educational subsidies $\tau$, under the conditions in Figure 1a. An increase in $\tau$ reduces capital per head for any given level of $e$ and increases $e$ for any given level of $k$. A reduction in education costs increases the rate of return from education and leads to a shift in demand and a consequent transfer of resources from physical to human capital. In the new equilibrium, capitallabour ratio unambiguously falls. But depending on the extent of the shift in the $\dot{e}=0$ schedule, the percentage of the educated will either rise or fall. It is a natural outcome that an increase in educational subsidies will reduce capital-deepening. Hence it is indeed paradoxical that under the conditions stated in Figures $1 \mathrm{~b}$ and $1 \mathrm{c}$, capitaldeepening might take place with an increase in $\tau$. Given the structure of our model, the reason is that an increase in such subsidies does not cause the education sector to expand relative to the contraction in the capital goods sector. This relative expansion and contraction in the two sectors, again, crucially depends on the movements in the unemployment rate which affects the demand for the two goods.

Under the conditions in Figure 1c, we get yet another paradoxical result that an increase in the propensity to save decreases the capital-labour ratio. With an increase in $s$, the $\dot{k}=0$ schedule shifts to the right. The $\dot{e}=0$ schedule, however, remains unchanged. For any given level of $e$, the capital-labour ratio increases. This expansion in the $\dot{Q}$-sector causes the education sector to expand from the production side. From the demand side, an increase in $k$ reduces the rate of return to capital and leads to a shift in the demand for education. Given the effects on $p$ and the assumptions on factor substitutability, $k$ falls and $e$ rises. Thus, it is the presence of two assets and the resulting portfolio decision along with the substitutability conditions in production that are responsible for such paradoxical results.

We have observed before, that growth affects costs of schooling. Hence, with parametric shifts, the long-run movements in the unemployment rate depend on the movements in $k, e$ and $p$. For example, in the situation described in Figure $1 \mathrm{c}$ an increase in the saving propensity generates strong forces to increase $\lambda$. But the final result depends on the associated movement in $p$.

Similar paradoxical results are stated in Table B where the steady state is a saddle-point. The reader can now easily provide for himself the reasons for such outcomes.

\section{SUMMARY OF RESULTS}

1. In a two-sector, three-input, two-asset model we get unusual Rybczynski effects. An increase in capital per head keeps output of the Solow-good unchanged but increases the proportion of the newly educated to total population. An increase in the educated/population ratio, however, decreases the output of the Solow-good sector and increases the proportion of the newly educated to total population, all without any factor intensity assumptions.
2. Under certain conditions, educational subsidies will increase the number of the educated unemployed in the short run.

3. Since costs of schooling change with growth, the stability property of the FR model cannot be regarded as a robust result.

4. We retain FR's paradoxical result that subsidies to education can raise the proportion of the uneducated in the long run.

5. We obtain a further paradoxical result that under certain conditions, an increase in the saving propensity will reduce both $k$ and $e$. Thus a decrease in the saving propensity causes a deepening of both physical and human capital.

6. An increase in educational subsidies may lead to capital-deepening in the long run.

7. An increase in educational subsidies may increase the long-run unemployment rate.

\section{REFERENCES}

1. Becker, G. S. Human Capital. New York: National Bureau of Economic Research. 1974.

2. Bhagwati, J. N., and T. N. Srinivasan. "Education in a 'Job Ladder' Model and the Fairness-in-Hiring Rule”. Journal of Public Economics. 1977.

3. Blaug, M., P. R. G. Layard and M. Woodhall. The Causes of Graduate Unemployment in India. United Kingdom. Allen Lane Press. 1969.

4. Calvo, G. A., and Carlos A. Rodriguez. "A Model of Exchange Rate Determination under Currency Substitution and Rational Expectations". Journal of Political Economy. 1978.

5. Findlay, R., and Carlos A. Rodriguez. "A Model of Economic Growth with Investment in Human Capital" Research in Human Capital and Development. Vol. II. Greenwich, Conn.: JAI Press. 1981.

6. Harris, J., and M. Todaro. "Migration, Unemployment and Development: A Two Sector Analysis". American Economic Review. 1970.

7. Razin, A. "Optimum Investment in Human Capital". Review of Economic Studies. 1972.

8. Obstfeld, M. "Macroeconomic Policy, Exchange Rate Dynamics and Optimal Asset Accumulation". Journal of Political Economy. 1981.

9. Solow, R. M. "A Contribution to the Theory of Economic Growth". Quarterly Journal of Economics. 1956. 


\section{Comments on}

\section{"Educated Unemployed, Educational Subsidies and Growth"}

In this paper, Datta Chaudhuri and Ali Khan tackle a problem vital for the underdeveloped countries. They discuss the economic factors that go into the decision whether education or direct employment is sought. In their extension of the model of Findlay and Rodriguez they find some unusual substitution effects. Their main results are that (a) a subsidy on education may lead to an increase in the number of the educated unemployed in the short run; (b) it would lead to a rise in the ratio of the uneducated to the educated in the long run; (c) an increase in the saving propensity may reduce the capital stock per capita; and (d) it may reduce the ratio of the educated to the uneducated in the economy. Chaudhuri and Khan have used various assumptions, both explicit and implicit, to arrive at these conclusions. I would like to comment very briefly on some points concerned with mathematics and then to discuss the underlying assumptions.

A slightly misleading use of partial derivatives on p. 6, after Eqs. (3.1) and (3.2), needs to be mentioned. Whereas these equations are for functions of two and three variables in one sense, they have been used as implicit functions of one variable only, $\bar{w}_{e}$ being treated as a separately given parameter. The problem with the equations as stated is that inversion of partial derivatives need not maintain the sign of the expression as it does for total derivatives, namely $\partial P / \partial r \#(\partial P)^{-1}$. It should be added that these conditions are not derived from Eqs. (3.1) and (3.2) but are requirements that the cost functions must satisfy.

Another problem in following the discussion is the derivation of Eqs. (3.6) and (3.7) from Eqs. (3.3) to (3.5). Here the cost function is regarded as a function of $\bar{w}_{e}$ as well. Then, using the minimality of cost functions we can replace

$$
E_{x} / X \text { by } \partial C_{x} / \partial \bar{w}_{e} \text { and } E_{q} / Q \text { by } \partial C_{q} / \partial \bar{w}_{e} \text {, etc. }
$$

Now, taking total differentials leads to the required result. Notice that in Eq. (3.7), $w_{e}$ should be replaced by $\bar{w}_{e}$. Also, the statement that output in the $Q$-sector is unaffected by change in the capital-labour ratio must be qualified by the requirement that price and the number of the educated divided by the total population be held constant. This statement follows directly, then, from Eq. (3.6). 
Let us now come to the assumptions, given in the order of increasing importance, which is the order in which they will be discussed. They are: (a) the education sector is less education-intensive than the other sectors; (b) that the educated are more productive than the uneducated; and (c) the uneducated are fully employed.

The first assumption is most unusual. In underdeveloped countries all that goes into the education sector is educated people. There is virtually no physical capital invested. More accurately, there is negligible physical capital invested in education compared with the "educated" manpower. Even in developed countries I can not imagine any sector which is more education-intensive than education. One can certainly conceive of such a situation but it does not exist to my knowledge. This is the assumption that leads to the expectation that educational subsidies could increase the number of the educated unemployed.

The second assumption is very commonly taken. However, it will really be valid if education is useful or relevant. All too often the so-called "education" in the Third World countries is not at all useful. The analysis would apply to technical training in the short run and to good general education in the long run. I will shortly return to this point.

The third assumption gives a very odd situation. The educated are unable to compete for the same jobs with the uneducated. Thus, education is regarded here as a gamble to obtain higher wages or lose wages altogether. Given this set-up, it is not surprising that since the educated compete among themselves for a limited number of jobs, anything which increases the number of the educated also increases the number of the educated unemployed. If, instead, we allowed for competition between the educated and the uneducated, we would, presumably, obtain the result arrived at by Gary Fields that an increase in the supply of the educated would increase the demand for them and could, hence, lead to a reduction in the number of the educated unemployed. If education is sound, this will surely hold true. Clearly, then, the last two assumptions are not entirely unrelated.

I would like to view the results of the paper in a slightly different way. What has been shown is that if education is meaningful the supply of the educated would increase the demand for them, but if it is not really relevant, subsidizing it would lead to an increase in the educated unemployed. Viewed this way, the work of Chaudhuri and Khan could provide an estimate of the economic utility of education. A break-up of education into two sectors - technical training and general education - could provide further insights. It would be worth while to look into these aspects in more detail.

Associate Professor, Asghar Qadir

Department of Mathematics, Quaid-i-Azam University, Islamabad 